\title{
Molecular Detection of blaOXA-type Carbapenemase Genes and Antimicrobial Resistance Patterns among Clinical Isolates of Acinetobacter baumannii
}

\author{
Maghsoud Kafshnouchi \\ Marzieh Safari² \\ Seyed Hamid Hashemi ${ }^{5}$ Mohammad Sina Alikhani ${ }^{6}$ \\ ${ }^{1}$ Department of Microbiology, Maragheh Islamic Azad University, \\ Maragheh, Iran \\ ${ }^{2}$ Department of Microbiology, Hamadan University of Medical \\ Sciences, Hamadan, Iran \\ ${ }^{3}$ Department of Biology, Faculty of Natural Sciences, University of \\ Tabriz, Tabriz, Iran \\ ${ }^{4}$ Department of Microbiology, Tehran University of Medical Sciences, \\ Tehran, Iran \\ ${ }^{5}$ Department of Infectious Diseases, Hamadan University of Medical \\ Sciences, Hamadan, Iran \\ ${ }^{6}$ Student Research Committee, Hamadan University of Medical \\ Sciences, Hamadan, Iran \\ ${ }^{7}$ Research Center for Molecular Medicine, Hamadan University of \\ Medical Sciences, Hamadan, Iran
}

Amir Khodavirdipour ${ }^{3}$

Abbas Bahador ${ }^{4}$ Massoud Saidijam ${ }^{7}$ Mohammad Yousef Alikhani ${ }^{20}$ Address for correspondence Mohammad Yousef Alikhani, PhD, Department of Microbiology, Faculty of Medicine, Hamadan University of Medical Sciences, Hamadan 65178-38736, Iran (e-mail: alikhani43@yahoo.com; alikhani@umsha.ac.ir).

Glob Med Genet 2022;9:118-123.

Abstract


Keywords
- Acinetobacter
baumannii
- nosocomial infection
- OXA-type
carbapenemase

Acinetobacter baumannii is a bacterium found in most places, especially in clinics and hospitals, and an important agent of nosocomial infections. The presence of class $D$ enzymes such as OXA-type carbapenemases in A. baumannii is proven to have a key function in resistance to carbapenem. The aim of the current study is to determine the blaOXA $_{\text {-type }}$ carbapenemase genes and antimicrobial resistance among clinically isolated samples of $A$. baumannii. We assessed 100 clinically isolated specimens of $A$. baumannii from patients in intensive care units of educational hospitals of Hamadan, West of Iran. The A. baumannii isolates' susceptibility to antibiotics was performed employing disk diffusion method. Multiplex polymerase chain reaction was used to identify the bla $a_{\text {OXA-24-like, }}$ bla OXA-23like, bla $a_{\text {OXA-58-like, }}$ and bla $a_{\text {OXA-57-like }}$ genes. The bla $a_{\text {OXA-23-like, }}$ bla OXA-24like, and $b a_{\text {OXA-58-like }}$ genes' prevalence were found to be 84,58 , and $3 \%$, respectively. The highest coexistence of the genes was for bla $a_{O X A-51 / 23}(84 \%)$ followed by bla $a_{O X A-51 / 24 l i k e}(58 \%)$. The bla $a_{O X A-51 / 23-l i k e}$ pattern of genes is a sort of dominant gene in resistance in $A$. baumannii from Hamadan hospitals. The highest resistance to piperacillin (83\%) and ciprofloxacin (81\%) has been observed in positive isolates of bla $a_{\text {OXA-23-like. The } A \text {. baumannii isolates with bla OXA-58-like }}$ genes did not show much resistance to antibiotics. Based on the results of the phylogenetic tree analysis, all isolates have shown a high degree of similarity. This study showed the high frequency of OXA-type carbapenemase genes among A. baumannii isolates from Hamadan hospitals, Iran. Thus, applying an appropriate strategy to limit the spreading of these strains and also performing new treatment regimens are necessary.

received

September 20, 2021

accepted

October 18, 2021
DOI https://doi.org/ 10.1055/s-0041-1740019. ISSN 2699-9404.

\section{(c) 2021. The Author(s).}

This is an open access article published by Thieme under the terms of the Creative Commons Attribution License, permitting unrestricted use, distribution, and reproduction so long as the original work is properly cited. (https://creativecommons.org/licenses/by/4.0/)

Georg Thieme Verlag KG, Rüdigerstraße 14, 70469 Stuttgart, Germany 


\section{Introduction}

Acinetobacter baumannii is an oxidase-negative, gram-negative, nonmotile, nonfermentative coccobacilli and it is found inside most places, especially in hospitals and other health care facilities. ${ }^{1-3}$ The bacterium is mostly originating from the intensive care units (ICUs). It can cause septicemia, infections of the skin, meningitis, endocarditis, urinary tract infections, soft tissues infections, and ventilator-associated pneumonia in patients in ICU wards. ${ }^{4-7}$ Therefore, infections caused by the bacterium need early and effective antimicrobial therapy. The carbapenems are the most effective antibacterial agents in the case of clinical isolates of $A$. baumannii. ${ }^{8}$ Nowadays, due to excessive and inappropriate use of these drugs, the resistance to carbapenems has increased. ${ }^{9}$ A. baumannii can become carbapenem resistant by the acquisition of plasmid-mediated carbapenem hydrolyzing classes of A, B, and D metallo- $\beta$-lactamase enzymes. ${ }^{10}$ Class D enzymes such as OXA-type carbapenemases, especially the intrinsic presence of bla $a_{\mathrm{OXA}-58-\text { like}}, b l a_{\mathrm{OXA}-24-\text { like, }}$

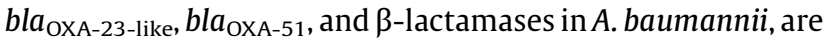
proven to have a vital role in resistance to carbapenem. ${ }^{11-13}$ The OXA-carbapenemase genes can be encoded by chromosome or plasmid and are mostly associated with insertion elements, particularly ISAbal. ${ }^{8}$ With the rise of pan-drugresistant (PDR) and multidrug-resistant (MDR) strains of $A$. baumannii all around the world, the bacterium has become a very serious threat for health care organizations. ${ }^{10,14}$ Thus, the current study focused to discover the blaOXA-type carbapenemase genes, which, according to previous studies, contribute to more antibiotic resistance among clinical isolates of $A$. baumannii.

\section{Materials and Methods}

\section{Bacterial Isolation and Identification}

The cross-sectional research has been performed on $100 \mathrm{~A}$. baumannii isolates from clinical specimens in ICU wards in educational hospitals of Hamadan, West of Iran, from December 2016 to December 2017. A. baumannii isolates were identified using the biochemical tests and polymerase chain reaction (PCR) targeting the carbapenemase gene of blaOXA51-like. ${ }^{15,16}$

\section{Susceptibility Testing}

The CLSI-Clinical and Laboratory Standards Institute-(CLSI, 2018) method of disk-agar diffusion ${ }^{17}$ and interpretation by CLSI breakpoint were used to measure the susceptibility of $A$. baumannii isolates to Meropenem (10 $\mu \mathrm{g})$, Imipenem (10 $\mu \mathrm{g})$, Amikacin $(30 \mu \mathrm{g})$, Gentamicin $(10 \mu \mathrm{g})$, Ciprofloxacin $(5 \mu \mathrm{g})$, Doxycycline $(30 \mu \mathrm{g})$, Piperacillin $(100 \mu \mathrm{g})$, Tobramycin (10 $\mu \mathrm{g})$, Cefepime $(30 \mu \mathrm{g})$, and Ampicillin/sulbactam $(20 \mu \mathrm{g})$ antimicrobial agents. ATCC 27853-Pseudomonas aeruginosa was deployed in susceptibility testing as the control strain.

\section{Multiplex-PCR Assay}

Alkaline lysis method was used for extraction of deoxyribonucleic acid (DNA). ${ }^{15}$ The primers for PCR amplification of bla $a_{\text {OXA-58-like, }}$ bla $a_{\text {OXA-23-like }}$, bla $_{\text {OXA-51-like, }}$ and bla OXA-24-like $_{\text {were }}$ used as described before (-Table 1). ${ }^{18}$

Multiplex-PCR was performed in a $50-\mu \mathrm{L}$ reaction volume containing $5 \mu \mathrm{L}$ PCR buffer $10 \mathrm{X}$ with $\mathrm{MgCl}_{2}, 5 \mu \mathrm{L}$ deoxynucleotide triphosphates $(2 \mathrm{~mm}), 2 \mu \mathrm{L}$ from each reverse and forward primers (10 pmol), $0.4 \mu \mathrm{L}$ Taq Polymerase $(5 \mathrm{U} / \mu \mathrm{L}), 6 \mu \mathrm{L}$ DNA template, and $29.6 \mu \mathrm{L}$ nuclease-free deionized water. The amplification conditions were as follows: initial denaturation at $94^{\circ}$ C for 5 minutes followed by 30 cycles at $94^{\circ} \mathrm{C}$ for 30 seconds, $53^{\circ}$ $\mathrm{C}$ for 40 seconds, and $72^{\circ} \mathrm{C}$ for 50 seconds and a final extension at $72^{\circ} \mathrm{C}$ for 6 minutes. Gel electrophoresis of the amplicons was performed on $1.5 \%$ agarose gel. The findings were analyzed employing a transilluminator device. Bands with 353 bp, 501 bp, $246 \mathrm{bp}$, and $599 \mathrm{bp}$ were the representatives of bla $a_{\text {OXA-51-like, }}$ bla $a_{\text {OXA-23-like, }}$ bla $a_{\text {OXA-24-like, and } b l a_{\text {OXA-58-like, }} \text {, respectively. }}$

\section{Sequencing}

Three PCR products of each gene, which was separately performed, were purified and sequenced directly by Sanger dideoxy-sequencing technology in two directions using a capillary DNA analyzer (Applied Biosystems, Waltham, Massachusetts, United States).

\section{Phylogenetic Analysis of OXA-type Variant}

The phylogenetic analysis was conducted independently for the OXA-type variant. The tree is drawn to scale, with branch lengths measuring the number of substitutions per site. The sequences were aligned and manually edited in consensus positions and compared with that of the sequences from

Table 1 Primer sequences used for multiplex polymerase chain reaction amplification of bla OXA genes variants

\begin{tabular}{|c|c|c|c|c|c|}
\hline \multicolumn{2}{|c|}{ Primer name } & $5^{\prime}$ to $3^{\prime}$ sequence prime & Product size (bp) & Annealing temperature $\left({ }^{\circ} \mathrm{C}\right)$ & Reference \\
\hline \multirow[t]{2}{*}{ OXA-51-like } & $\mathrm{F}$ & TAATGCTTTGATCGGCCTTG & \multirow[t]{2}{*}{353} & \multirow[t]{2}{*}{53} & \multirow[t]{2}{*}{ Woodford $(2006)^{18}$} \\
\hline & $\mathrm{R}$ & TGGATTGCACTTCATCTTGG & & & \\
\hline \multirow[t]{2}{*}{ OXA-23-like } & $\mathrm{F}$ & GATCGGATTGGAGAACCAGA & \multirow[t]{2}{*}{501} & \multirow[t]{2}{*}{53} & \multirow[t]{2}{*}{ Woodford $(2006)^{18}$} \\
\hline & $\mathrm{R}$ & ATTTCTGACCGCATTTCCAT & & & \\
\hline \multirow[t]{2}{*}{ OXA-24-like } & $\mathrm{F}$ & GGTTAGTTGGCCCCCTTAAA & \multirow[t]{2}{*}{246} & \multirow[t]{2}{*}{53} & \multirow[t]{2}{*}{ Woodford $(2006)^{18}$} \\
\hline & $\mathrm{R}$ & AGTTGAGCGAAAAGGGGATT & & & \\
\hline \multirow[t]{2}{*}{ OXA-58-like } & $\mathrm{F}$ & AAGTATTGGGGCTTGTGCTG & \multirow[t]{2}{*}{599} & \multirow[t]{2}{*}{53} & \multirow[t]{2}{*}{ Woodford (2006) ${ }^{18}$} \\
\hline & $\mathrm{R}$ & ССССТСТGCGСТСТАСАTAC & & & \\
\hline
\end{tabular}


GenBank. A phylogenetic tree was built by the maximum likelihood method utilizing the Tamura-Nei model with Mega software (v.7). ${ }^{19}$

\section{Statistical Analysis}

Statistical analysis was done using Statistical Package for the Social Sciences 23.0 (SPSS, Chicago, Illinois, United States). The Pearson chi-squared test and Fisher's exact test were used to analyze the qualitative data. All $p$-values $<0.05$ were considered statistically significant.

\section{Results}

The highest resistance to piperacillin (83\%) and ciprofloxacin (81\%) has been observed in blaOXA23-like, and the highest resistance and sensitivity were observed for ciprofloxacin (57\%) and ampicillin/sulbactam (28\%) in blaOXA-24-like positive A. baumannii isolates, respectively. The A. baumannii isolates with blaOXA-58-like genes did not show much resistance to antibiotics. Considering the presence of the studied genes, 3,58 , and $84 \%$ of the 100 samples were carrying blaOXA-58-like, blaOXA-24-like, and blaOXA-23like genes, respectively (-Fig. 1 and -Table 2). Among the 100 A. baumannii isolates, $97.9 \%$ of the imipenem-resistant isolates were positive for at least one OXA-type gene. Moreover, $95.9 \%$ and $1 \%$ of the meropenem and colistin sulfate resistant isolates were carrying OXA-type genes.

\section{Results of Phylogenetic Tree Analysis of OXA-type Variant} The sequences received from the isolates were confirmed as the OXA-type variants and were deposited in the GenBank under the accession numbers as follows: bla OXA-51-like: $_{\text {in }}$

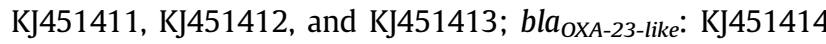

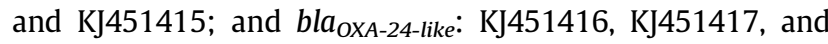
KJ451418 (-Fig. 2). Analysis of the phylogenic tree demonstrates that all isolates have shown a high degree of similarity.

\section{Correlation between Contributions of blaoxa Genes with Antibiotic Resistance}

The relationship between blaOXA-types and resistance to different antibiotics was determined by statistical analysis.

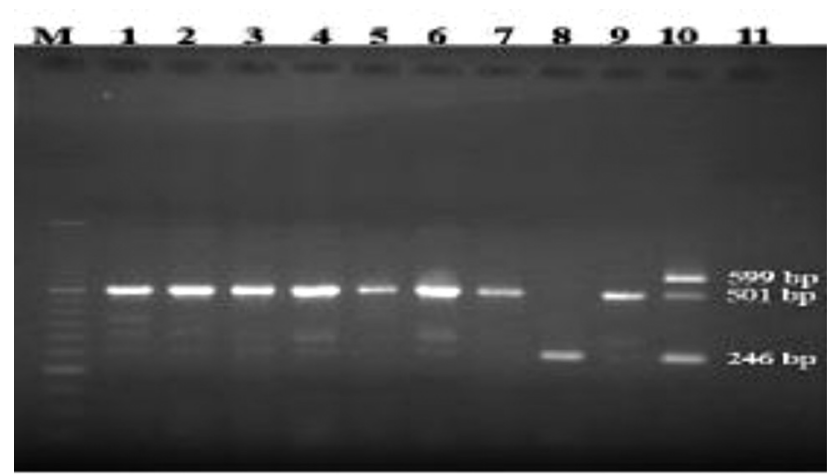

Fig. 1 Gel electrophoresis of the blaOXA gene among the Acinetobacter baumannii isolates. M: 50 bp marker; 1-10: the isolates; 11 : negative control. Bands with 501 bp, 246 bp, and 599 bp are the representatives of blaOXA-23-like, blaOXA-24-like, and blaOXA-58like, respectively.
Table 2 OXA-type patterns among carbapenem-resistant Acinetobacter baumannii isolates

\begin{tabular}{|l|l|}
\hline Gene pattern & No (\%) \\
\hline OXA-51 & $100(100)$ \\
\hline OXA-23 & $84(84)$ \\
\hline OXA-58 & $3(3)$ \\
\hline OXA-24 & $58(58)$ \\
\hline OXA-51/OXA-23 & $84(84)$ \\
\hline OXA-51/OXA-24 & $58(58)$ \\
\hline OXA-51/OXA-58 & $3(3)$ \\
\hline OXA-51/OXA-23/OXA-24 & $5(5)$ \\
\hline OXA-51/OXA-24/OXA-58 & $2(2)$ \\
\hline OXA-51/OXA-23/OXA-24/OXA-58 & $1(1)$ \\
\hline
\end{tabular}

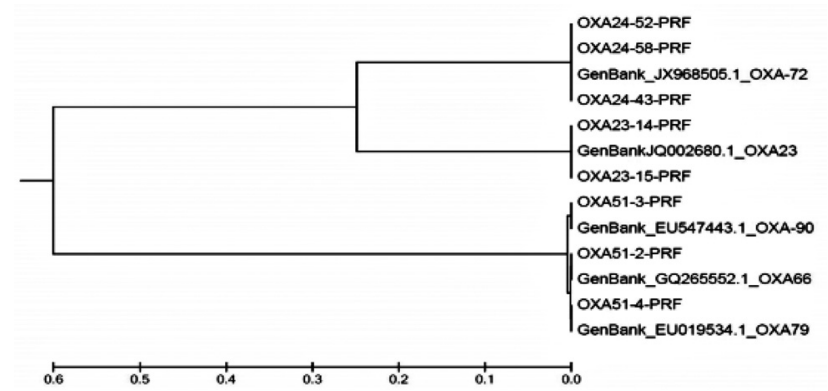

Fig. 2 Phylogenetic tree built based on the sequence isolates by maximum likelihood method using the Tamura-Nei model. Based on the results, all isolates have shown a high degree (95-100\%) of similarity.

The prevalence of oxacillinases enzymes encoding genes in antibiotic-resistant isolates was higher than the susceptible strains, but there was no statistically significant relationship (-Table 3 ).

\section{Discussion}

Currently, carbapenem resistance in A. baumannii isolates has become a worldwide problem. This study's results demonstrated that significant numbers of clinical isolates of $A$. baumannii, especially resistant to imipenem and meropenem isolates, were affirmative for the variety of OXA gene expressions. Commonly, the carbapenem antibiotics are highly active against $A$. baumannii isolates and resistant to $\beta$-lactamase enzymes. However, the resistance to these compounds is a problematic issue and is not a result of the presence of a distinct mechanism, while a combination of diverse mechanisms such as enzymatic and nonenzymatic ones are involved. The most significant mechanism of resistance to carbapenems is the enzymatic hydrolysis, arbitrated by the carbapenemases. ${ }^{11,20}$ Recently, the number of $\beta$ lactamase enzymes in class $D$ has increased significantly. Some of the OXA-type carbapenemases are widely found in $A$. baumannii isolates. However, many of the OXA-type 


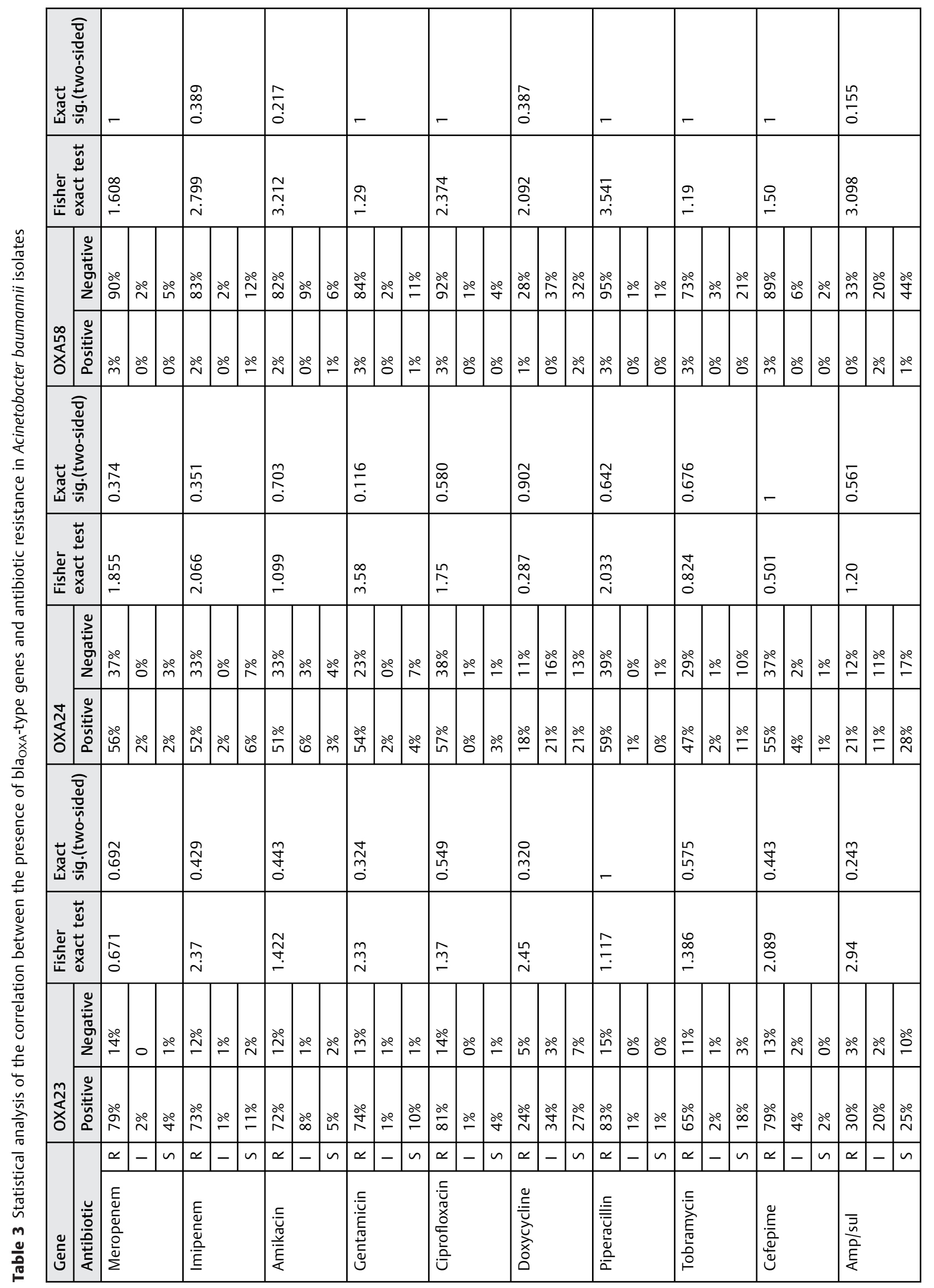


carbapenemases illustrate simply weak catalytic activity, but resistance to carbapenems may be caused by a combined action of different OXA-type carbapenemase. ${ }^{21}$ Feizabadi et al in 2008 studied the susceptibility to antimicrobial and blaOXA genes distribution among Acinetobacter spp. in Tehran hospitals. They reported the coexistence of $b l a_{O X A-}$

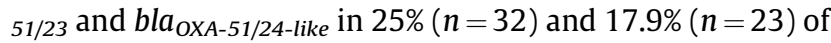
their studied isolates, respectively. Over $70 \%$ of their studied carbapenem-resistant isolates had at least two genes encoding OXA-type carbapenemase. ${ }^{22}$ In our study, the highest coexistence was for $b l a_{\text {OXA-51/23 }}(84 \%)$ followed by bla $_{\text {OXA- }}$ 51/24-like (58\%), which is considerably higher than their report from Tehran and indicates an elevation in the prevalence of $A$. baumannii isolates carrying these genes over the time. In the current research, comparable to another research performed in Iran, the most commonly found OXA-type carbapenemase was OXA-23 among other carbapenem-resistant isolates, next to OXA-24. ${ }^{23,24}$ Zafari et al reported a high prevalence of OXAtype carbapenemases among $A$. baumannii isolates in Tehran in 2017. They studied bla $a_{\text {OXA-51-like, }}$ bla OXA-58-like, $_{\text {OXA-23-like, }}$ and bla $a_{\text {OXA-24-like }}$ genes among 100 isolates of carbapenemresistant $A$. baumannii. All of their studied carbapenem-resistant $A$. baumannii isolates were MDR and extensively drugresistant and even $2 \%$ of the isolates were PDR. The bla $a_{O X A-24-l i k e}$ and $b l a_{O X A-23-l i k e}$ prevalence genes were reported to be $22 \%$ and $81 \%$, respectively. They concluded that there are very few therapeutic options for the treatment of carbapenem-resistant A. baumannii infections. ${ }^{23}$ In the present study, just similar to the findings of Zafari et al in Tehran, 84, 58, and 3\% of the $A$. baumannii isolates from Hamadan, west of Iran, were carrying bla $_{\text {OXA-23-like, }}$ bla OXA-24-like, and bla $_{\text {OXA-58-like }}$ genes, respectively. The very high prevalence of drug resistance among $A$. baumannii isolates was reported in Hamadan in 2013. ${ }^{24}$ Bardbari et al investigated the OXA-type gene presence including $b_{O X A}$ 58 and bla $_{\text {OXA-23 }}$, blaOXA -24 among 75 clinical and 32 environmental strains of the $A$. baumannii isolates in Hamadan in 2017. Their results showed that $80.4,30.8,0$, and $30.8 \%$ of their studied $A$. baumannii isolates have bla $_{\text {OXA-23/24, blaOXA }}$-24, $b l a_{\text {OXA-23, }}$, and $b l a_{\text {OXA-58 }}$ genes. ${ }^{25}$ Their results are similar to the finding of the present study. Given the fact that both studies are conducted in the same area but on different isolates, the similar results can be explained. In a study that was prepared by Zowawi et al, OXA-23 was identified as the highest type (91.5\%) of carbapenemases in carbapenem-resistant A. baumannii isolates from hospitals of Bahrain, Saudi Arabia, Oman, Kuwait, United Arab Emirates, and Qatar followed by OXA-24 (4.3\%). ${ }^{26}$ Also, research works from other countries have reported that OXA-23 as a dominant type in carbapenem-resistant isolates has been accompanying outbreaks. ${ }^{27,28}$ Similar to our results, some studies have reported the low prevalence of OXA-58 among carbapenem-resistant isolates from the east $(0.5 \%)$, and northwest of Iran (3.2\%). ${ }^{26,29}$ The outcome of our research confirmed the high prevalence of OXA-type carbapenemase between carbapenem antibiotic-resistant $A$. baumannii bacteria; furthermore, correct prescription of antibiotics and effective infection control monitors for preventing the extent of resistant isolates are required.

\section{Conclusion}

This study's results demonstrated that carbapenem resistance is increasing among A. baumannii clinical isolates in our area and is often associated with multidrug resistance. Moreover, the diversity of blaOXA genes was high among these isolates and OXA-23 is the most important carbapenemase mechanism responsible for the resistance phenotype.

\section{Consent for Publication}

All authors consented for publication of the above paper.

\section{Availability of Data and Material}

All data generated or analyzed during this study are included in this published article.

\section{Authors' Contributions}

M.Y.A. designed the study, edited the manuscript. M.S. and A.B. were scientific advisor on molecular genetics section. M.K., M.S., and M.S.A. collaborated in collecting samples and doing experiments. S.H.H. collaborated on patient introduction and clinical examination. A.K. wrote the scientific draft and checked the English use and grammar of the manuscript.

\section{Funding}

The present study was supported financially by the ViceChancellor of Research and Technology, Hamadan University of Medical Sciences, Hamadan, Iran.

\section{Conflict of Interest}

None declared.

\section{Acknowledgment}

The authors would like to acknowledge the Vice-Chancellor of Research and Technology, Hamadan University of Medical Sciences, Hamadan, Iran, for the financial support to the present study.

\section{References}

1 Perez F, Hujer AM, Hujer KM, Decker BK, Rather PN, Bonomo RA. Global challenge of multidrug-resistant Acinetobacter baumannii. Antimicrob Agents Chemother 2007;51(10):3471-3484

2 Yeom J, Shin JH, Yang JY, Kim J, Hwang GS. (1)H NMR-based metabolite profiling of planktonic and biofilm cells in Acinetobacter baumannii 1656-2. PLoS One 2013;8(03):e57730

3 Poirel L, Bonnin RA, Nordmann P. Genetic basis of antibiotic resistance in pathogenic Acinetobacter species. IUBMB Life 2011;63(12):1061-1067

4 Gulati S, Kapil A, Das B, Dwivedi SN, Mahapatra AK. Nosocomial infections due to Acinetobacter baumannii in a neurosurgery ICU. Neurol India 2001;49(02):134-137

5 Rodríguez Guardado A, Maradona JA, Asensi V, et al. [Postsurgical meningitis caused by Acinetobacter baumannii: study of 22 cases and review of the literature]. Rev Clin Esp 2001;201(09):497-500

6 Wang KW, Chang WN, Huang CR, et al. Post-neurosurgical nosocomial bacterial meningitis in adults: microbiology, clinical features, and outcomes. J Clin Neurosci 2005;12(06):647-650

7 Krol V, Hamid NS, Cunha BA. Neurosurgically related nosocomial Acinetobacter baumannii meningitis: report of two cases and literature review. J Hosp Infect 2009;71(02):176-180 
8 Poirel L, Naas T, Nordmann P. Diversity, epidemiology, and genetics of class D beta-lactamases. Antimicrob Agents Chemother 2010;54(01):24-38

9 Shahcheraghi F, Aslani MM, Mahmoudi H, et al. Molecular study of carbapenemase genes in clinical isolates of Enterobacteriaceae resistant to carbapenems and determining their clonal relationship using pulsed-field gel electrophoresis. J Med Microbiol 2017; 66(05):570-576

10 Bertini A, Poirel L, Mugnier PD, Villa L, Nordmann P, Carattoli A. Characterization and PCR-based replicon typing of resistance plasmids in Acinetobacter baumannii. Antimicrob Agents Chemother 2010;54(10):4168-4177

11 Opazo A, Domínguez M, Bello H, Amyes SG, González-Rocha G. OXA-type carbapenemases in Acinetobacter baumannii in South America. J Infect Dev Ctries 2012;6(04):311-316

12 Brown S, Young HK, Amyes SG. Characterisation of OXA-51, a novel class D carbapenemase found in genetically unrelated clinical strains of Acinetobacter baumannii from Argentina. Clin Microbiol Infect 2005;11(01):15-23

13 Higgins PG, Poirel L, Lehmann M, Nordmann P, Seifert H. OXA-143, a novel carbapenem-hydrolyzing class $\mathrm{D}$ beta-lactamase in Acinetobacter baumannii. Antimicrob Agents Chemother 2009;53 (12):5035-5038

14 Howard A, O'Donoghue M, Feeney A, Sleator RD. Acinetobacter baumannii: an emerging opportunistic pathogen. Virulence 2012;3(03):243-250

15 Safari M, Mozaffari Nejad AS, Bahador A, Jafari R, Alikhani MY. Prevalence of ESBL and MBL encoding genes in Acinetobacter baumannii strains isolated from patients of intensive care units (ICU). Saudi J Biol Sci 2015;22(04):424-429

16 Turton JF, Woodford N, Glover J, Yarde S, Kaufmann ME, Pitt TL. Identification of Acinetobacter baumannii by detection of the blaOXA-51-like carbapenemase gene intrinsic to this species. J Clin Microbiol 2006;44(08):2974-2976

17 CLSI. Performance Standards for Antimicrobial Susceptibility Testing. 28th edition. CLSI Supplement M100. Wayne, PA: Clinical and Laboratory Standards Institute; 2018

18 Woodford N, Ellington MJ, Coelho JM, et al. Multiplex PCR for genes encoding prevalent OXA carbapenemases in Acinetobacter spp. Int J Antimicrob Agents 2006;27(04):351-353
19 Tamura K, Nei M. Estimation of the number of nucleotide substitutions in the control region of mitochondrial DNA in humans and chimpanzees. Mol Biol Evol 1993;10(03):512-526

20 Queenan AM, Bush K. Carbapenemases: the versatile beta-lactamases. Clin Microbiol Rev 2007;20(03):440-458table of contents.

21 Walther-Rasmussen J, Høiby N. OXA-type carbapenemases. J Antimicrob Chemother 2006;57(03):373-383

22 Feizabadi MM, Fathollahzadeh B, Taherikalani M, et al. Antimicrobial susceptibility patterns and distribution of blaOXA genes among Acinetobacter spp. isolated from patients at Tehran hospitals. Jpn J Infect Dis 2008;61(04):274-278

23 Zafari M, Feizabadi MM, Jafari S, Abdollahi A, Sabokbar A. High prevalence of OXA-type carbapenemases among Acinetobacter baumannii strains in a teaching hospital of Tehran. Acta Microbiol Immunol Hung 2017;64(04):385-394

24 Safari M, Saidijam M, Bahador A, Jafari R, Alikhani MY. High prevalence of multidrug resistance and metallo-beta-lactamase $(\mathrm{M} \beta \mathrm{L})$ producing Acinetobacter baumannii isolated from patients in ICU wards, Hamadan, Iran. J Res Health Sci 2013;13(02): 162-167

25 Bardbari AM, Arabestani MR, Karami M, et al. Highly synergistic activity of melittin with imipenem and colistin in biofilm inhibition against multidrug-resistant strong biofilm producer strains of Acinetobacter baumannii. Eur J Clin Microbiol Infect Dis 2018; 37(03):443-454

26 Zowawi HM, Sartor AL, Sidjabat HE, Balkhy HH, Walsh TR, Al Johani SM, et al. Molecular epidemiology of carbapenemresistant Acinetobacter baumannii isolates in the Gulf Cooperation Council States: dominance of OXA-23-type producers. J Clin Microbiol 2015;53:896-903

27 Merino M, Poza M, Roca I, et al. Nosocomial outbreak of a multiresistant Acinetobacter baumannii expressing OXA-23 carbapenemase in Spain. Microb Drug Resist 2014;20(04):259-263

28 Dettori M, Piana A, Deriu MG, et al. Outbreak of multidrugresistant Acinetobacter baumannii in an intensive care unit. New Microbiol 2014;37(02):185-191

29 Kooti S, Motamedifar M, Sarvari J. Antibiotic resistance profile and distribution of oxacillinase genes among clinical isolates of Acinetobacter baumannii in Shiraz teaching hospitals, 2012-2013. Jundishapur J Microbiol 2015;8(08):e20215 